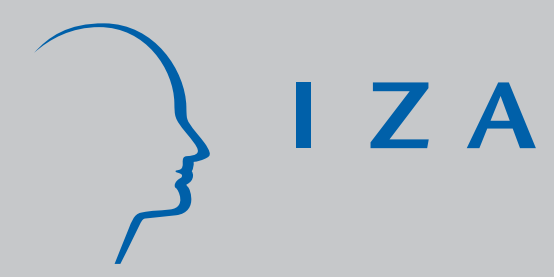

IZA DP No. 1722

Bargaining Frictions and Hours Worked

Stéphane Auray

Samuel Danthine

August 2005

Forschungsinstitut

zur Zukunft der Arbeit

Institute for the Study

of Labor 


\title{
Bargaining Frictions and Hours Worked
}

\author{
Stéphane Auray \\ Université Charles-de-Gaulle Lille 3, \\ GREMARS and CIRPÉE \\ Samuel Danthine \\ Université du Québec à Montréal, \\ CIRPÉE and IZA Bonn
}

\section{Discussion Paper No. 1722 August 2005}

\author{
IZA \\ P.O. Box 7240 \\ 53072 Bonn \\ Germany \\ Phone: +49-228-3894-0 \\ Fax: +49-228-3894-180 \\ Email: iza@iza.org
}

\begin{abstract}
Any opinions expressed here are those of the author(s) and not those of the institute. Research disseminated by IZA may include views on policy, but the institute itself takes no institutional policy positions.

The Institute for the Study of Labor (IZA) in Bonn is a local and virtual international research center and a place of communication between science, politics and business. IZA is an independent nonprofit company supported by Deutsche Post World Net. The center is associated with the University of Bonn and offers a stimulating research environment through its research networks, research support, and visitors and doctoral programs. IZA engages in (i) original and internationally competitive research in all fields of labor economics, (ii) development of policy concepts, and (iii) dissemination of research results and concepts to the interested public.
\end{abstract}

IZA Discussion Papers often represent preliminary work and are circulated to encourage discussion. Citation of such a paper should account for its provisional character. A revised version may be available directly from the author. 


\section{ABSTRACT}

\section{Bargaining Frictions and Hours Worked ${ }^{*}$}

A matching model with labor/leisure choice and bargaining frictions is used to explain (i) differences in GDP per hour and GDP per capita, (ii) differences in employment, (iii) differences in the proportion of part-time work across countries. The model predicts that the higher the level of rigidity in wages and hours the lower are GDP per capita, employment, part-time work and hours worked, but the higher is GDP per hours worked. In addition, it predicts that a country with a high level of rigidity in wages and hours and a high level of income taxation has higher GDP per hour and lower GDP per capita than a country with less rigidity and a lower level of taxation. This is due mostly to a lower level of employment. In contrast, a country with low levels of rigidity in hour and in wage setting but with a higher level of income taxation has a lower GDP per capita and a higher GDP per hour than the economy with low rigidity and low taxation, because while the level of employment is similar in both economies, the share of part-time work is larger.

JEL Classification: E24, J22, J30, J41, J50, J64

Keywords: models of search and matching, bargaining frictions, economic performance, labor market institutions, part-time jobs, labor market rigidities

Corresponding author:

Samuel Danthine

Université du Québec à Montréal

Département des Sciences Économiques

Case postale 8888, succursale Centre-Ville

Montréal (QC) H3C 3P8

Canada

Email: danthine.samuel@uqam.ca

\footnotetext{
* We would like to thank Mark Bils, Jean-Pierre Danthine, Jeremy Greenwood, Lance Lochner, Miguel Molico, Javier Ortega, Peter Rupert, Etienne Wasmer, participants at the WEGMaNS conference in Rochester (2003), at the macro-workshop at the University of Western Ontario (2003) and at the SED and ESEM summer meetings (2004) for helpful comments. The traditional disclaimer applies.
} 


\section{Introduction}

This paper belongs to a strand of the literature that explores the impact on economic performance of labor market institutions. It goes beyond the usual Europe versus US comparison by introducing a wider range of measures of economic performance and a mix of labor market institutions and labor income taxation. Specifically, it is argued that, within a two-sided search framework, ex-ante heterogeneity on both sides of the labor market, labor/leisure choices, bargaining frictions on wages and hours worked, and labor income taxation are crucial in explaining economic performance. Table 1 provides a summary evaluation of labor market arrangements in France, the Netherlands and the US, as well as four measures of economic performance.

Table 1: Economic Performance and Labor Market Characteristics

\begin{tabular}{lccc}
\hline \hline & France & Netherlands & US \\
\hline GDP per capita & 77 & 82 & 100 \\
GDP per hour & 103 & 106 & 100 \\
Employment rate (\%) & 62 & 73 & 72 \\
Part time (\%) & 13.7 & 33.9 & 13.4 \\
\hline Flexibility: wages & - & + & ++ \\
Flexibility: hours & - & + & ++ \\
Labor income taxation & + & + & - \\
\hline \hline
\end{tabular}

Notes: All data from the OECD data base for 2002. GDP per capita and GDP per hour are expressed relative to the US.

In terms of economic performance, the focus is on the following facts. First, GDP per capita is higher in the US than it is in Europe. Second, GDP per hour is higher in France and the Netherlands than it is in the US. Third, employment is much higher in the US and in the Netherlands than it is in France. Fourth, a large proportion of jobs in the Netherlands is part-time, which is not the case in either of the other countries.

In terms of labor market institutions and taxation, the US is undoubtedly the country with the most flexible labor market. The share of workers covered by wage bargaining is very low and the level of coordination between unions and employers is low. There is no legal maximum number of hours worked and the level of income taxation is low. The Netherlands have a more flexible labor market than France. The share of workers covered by wage bargaining is high in both countries, and a legal maximum number of hours worked is imposed by law. However, 
while in France there is a low level of coordination between the unions and the employers, there is a high level of coordination in the Netherlands. As argued by Nickell and van Ours (2000), this high level of coordination in the Netherlands leads to a higher degree of flexibility of the labor market. Furthermore, wage bargaining takes place at smaller intervals in the Netherlands than in France. In addition, agreements between the unions, the employers and the government in the Netherlands in the early 1980's have led to more flexibility in the choice of hours worked in that country as the union gave up their resistance to part-time jobs (see Nickell and van Ours (2000) for a discussion). Finally, labor income taxation in both France and the Netherlands is high. To summarize, the US and France represent two extremes in terms of labor market flexibility and in terms of labor income taxation. The Netherlands is an intermediate case with a flexible labor market but with a high level of taxation.

A quantitative two-sided search model with the following four characteristics is considered. First, there is ex-ante heterogeneity in both worker and firm types, and they are affected by idiosyncratic shocks. Employment in the model can be viewed as a match between a firm and a worker. Because of ex-ante heterogeneity, matches may be of different quality. This results in a situation in which high levels of employment can translate in more or less production per hour depending on the quality of sorting in the economy. In particular, an increase in the level of unemployment has two opposite effects on production. The fall in employment has a negative effect on production. The improvement in sorting due to the destruction of low quality matches has a positive one. Second, it is assumed that firms and workers may bargain over both hourly wages and hours worked. Labor/leisure choice introduces the possibility to work part-time when a pair matches. Third, the bargaining process is subject to frictions: firms and workers engaged in a match cannot renegotiate every period, but they know the probability with which they will be allowed to bargain in the future. Given the idiosyncratic shocks they face, firms and workers may want to readjust the number of hours they work and the corresponding hourly wage. This is not always possible, however, because of the bargaining frictions. These frictions thus create a distortion in both the choice to work or not to work and in the choice of the length of the working day. ${ }^{1}$ Fourth, differences in

\footnotetext{
${ }^{1}$ The assumption of bargaining frictions is also useful to link the model with a recent trend in the search and matching literature. A number of recent papers have shown that wage rigidities are necessary for a search model to explain the business cycles facts (see Shimer $(2004,2005)$ and Hall $(2003,2005)$ ). If wage rigidities are necessary to explain short-run fluctuations, it is preferable that it not be detrimental in explaining long-run facts.
} 
labor income taxation are introduced. Taxes distort the value of employment for workers. For similar levels of rigidities, an increase in the labor income tax induces some workers to switch from full-time to part-time employment, others to abandon their full-time jobs, and still others to quit their part-time jobs.

The model predicts that the higher the level of rigidity in wages and hours, the lower are GDP per capita, employment, part-time work and hours worked, but the higher is GDP per hours worked. This replicates the differences between France and the Netherlands. The model also predicts that a country with a high level of rigidity in wages and hours and a high level of income taxation has a higher GDP per hour and a lower GDP per capita than a country with less rigidity and a lower level of taxation. This is due mostly to a lower level of employment and better sorting (and not to a higher degree of part-time work). The model can thus replicate the differences between France and the US. In contrast, a country with low levels of rigidity in hour and in wage setting but with a higher level of income taxation has a lower GDP per capita and a higher GDP per hour than the economy with low rigidity and low taxation. The reason is that while the level of employment is similar, part-time work is more prevalent and sorting is increased. This replicates the differences between the Netherlands and the US.

In substance, using the model to filter observations, the US is a country with a very flexible labor market and a low level of income taxation, resulting in a high level of employment. This implies that matches of high quality cohabit with matches of lesser quality (i.e. there is little sorting) in this economy. Hence, while GDP per capita is high, GDP per hour is relatively low. In contrast, France is a country with high levels of rigidity and income taxation resulting in a lower level of employment but better sorting. In terms of economic performance, GDP per capita is lower, but GDP per hour is higher, than in the US. Finally, the Netherlands are characterized by a flexible labor market and a high level of income taxation. Employment is high in that country because of the flexibility of the labor market. High taxes, however, imply that a large share of the jobs are part-time. They also force a high level of sorting, as some prospective low quality matches refuse to engage in production due to the tax distortion. In terms of economic performance, GDP per capita is low because much of the employment is part-time. GDP per hour is high, however, both because of the high share of part-time jobs and the higher degree of sorting. 
The paper is organized as follows. In Section 2, data on economic performance and labor market institutions are presented for France, the Netherlands, and the US. The model is described in Section 3. The economy is parameterized, and the effects of changes in the probability of recontracting and in the rate of taxation are presented and analyzed. Finally, the relative importance of the rigidity in wages and the rigidity in hours choices to the results are presented. A final section concludes.

\section{Economic Performance and Labor Market Institutions}

In this section, more details about economic performance and labor market institutions for the US, the Netherlands, and France are provided.

\subsection{Economic Performance}

Hours worked, GDP per capita, employment and labor force participation for the period 1970 to 2000 for the US and France, for the period 1985 to 2000 for the Netherlands are traced in Figure $1 .^{2}$ Notice that, while France and the US had a similar total number of hours worked in 1970, hours have decreased steadily ever since in France while they have only decreased partially in the US. In the same time, the employment rate remained relatively stationary in France, but increased in the US. All this translates in an increase in GDP per hour in France relative to the US. Finally, labor force participation increases in both countries, but much less in France than in the US. The US has the highest level of per capita output, but France and the Netherlands are more efficient when one looks at production per hour. ${ }^{3}$ From the mideighties to today, hours worked in the Netherlands follow the French trend, but employment shoots up to US levels. This results in a high level of GDP per hour coupled with a high level of employment. In addition, labor force participation is similar to participation in the US.

These features of the data for the Netherlands can mostly be attributed to an increased flexibility regarding part-time work in the Netherlands. ${ }^{4}$ Data on part-time jobs as a proportion of all jobs in 2002 can be read in Table 2. In addition to the numbers for the whole population, data for three categories of age is given. The Netherlands have the highest pro-

\footnotetext{
${ }^{2}$ All data used here is from the OECD statistical database. Some variables are not available before 1985 for the Netherlands.

${ }^{3}$ GDP per hour and GDP per capita, relative to the US, for all three countries from 1950 to today is represented in Figure 2.

${ }^{4}$ Part-time jobs are defined by the OECD as jobs for which the laborer works less than 30 hours a week.
} 
Figure 1: Economic Performance
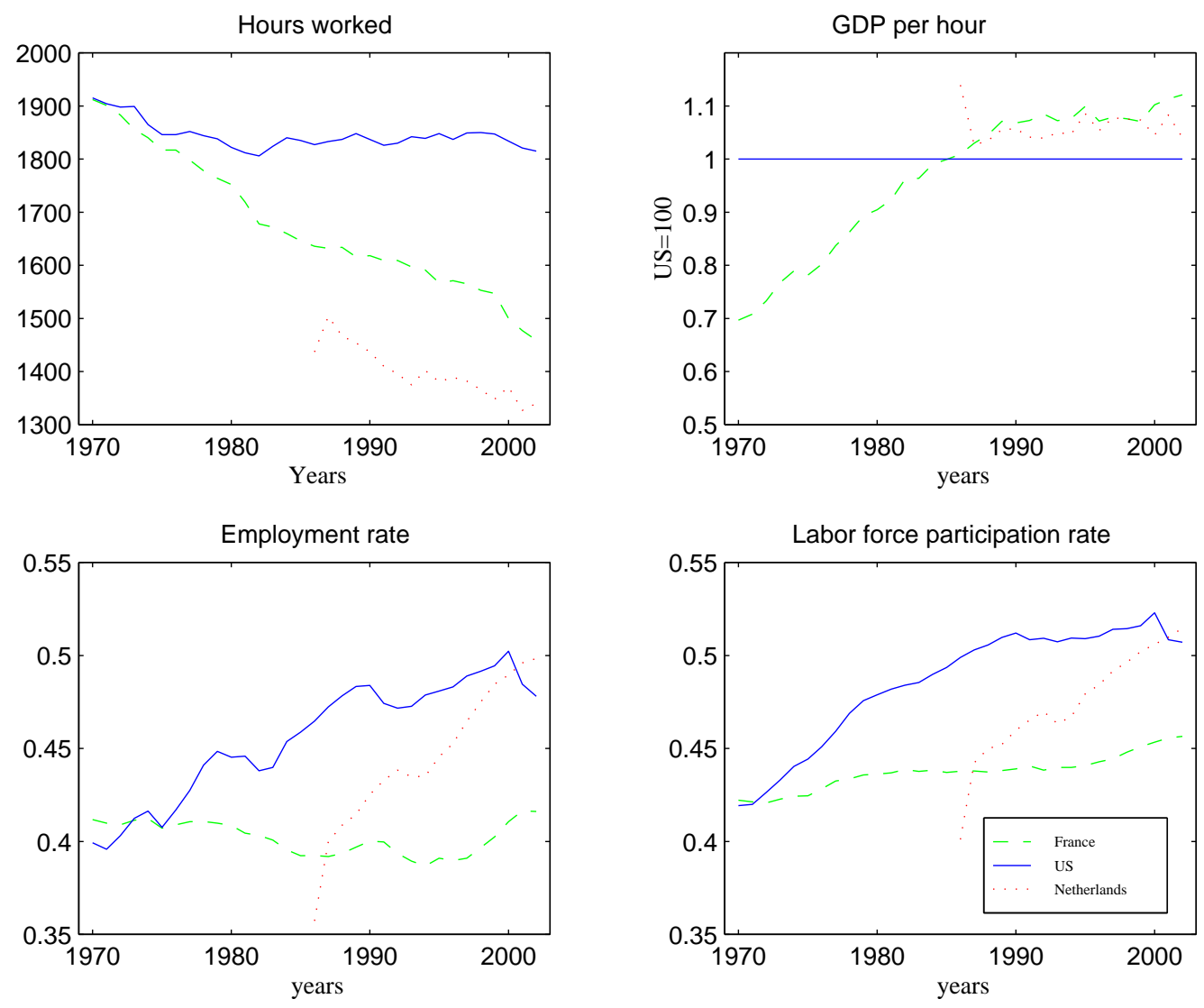

Source: OECD Statistical database. 
Figure 2: GDP per capita and per hour
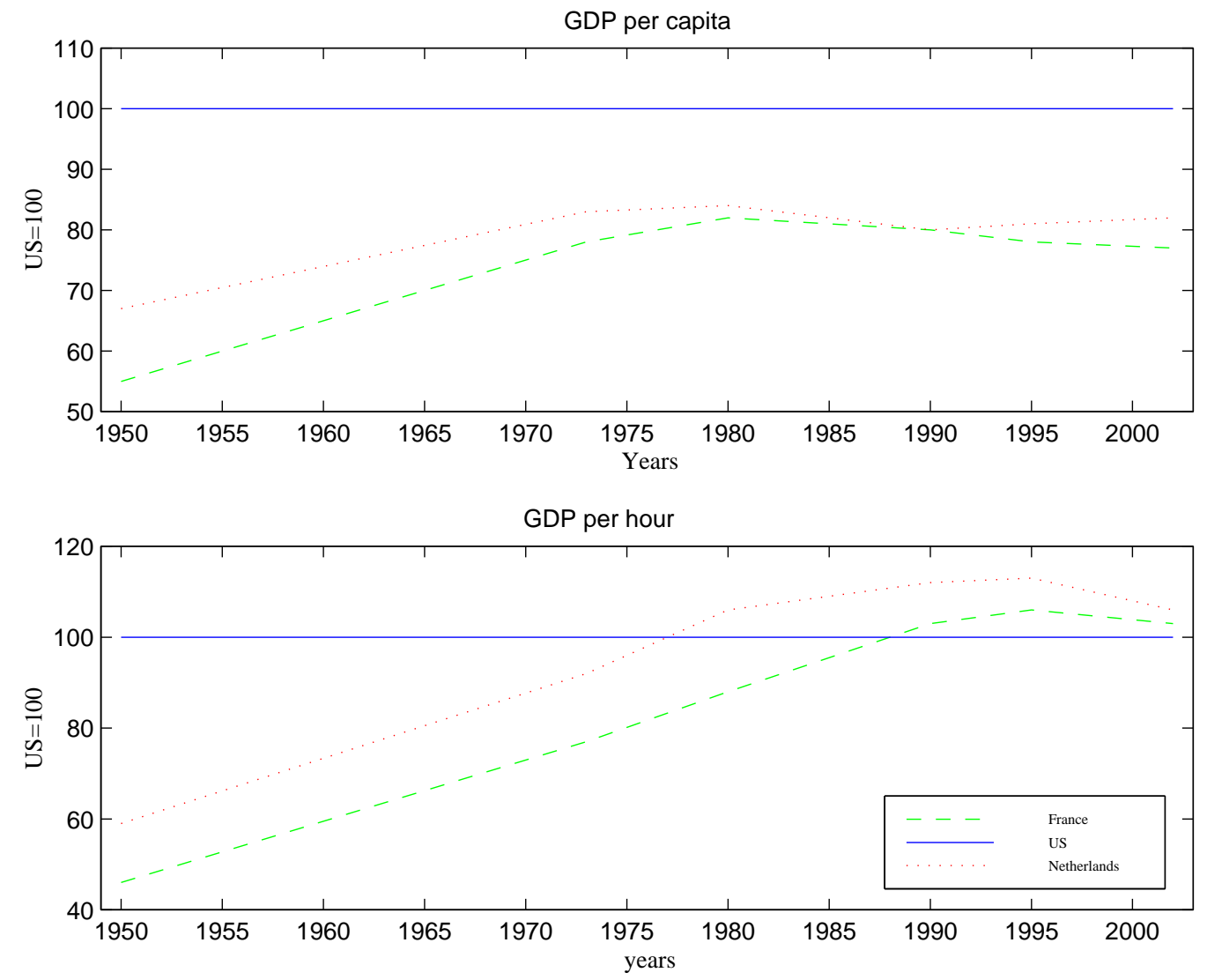

Source: OECD Statistical database. 
portion of part-time jobs in the whole population $(33.9 \%) .{ }^{5}$ In the other countries, part-time employment is much less prevalent. Another point can be made from looking across age categories. The use of part-time work is highest in the 15-24 age category. Partial work days are less present in the age category 25-54, and increases again in the population of age 55 and more. ${ }^{6}$ Looking now across gender, one observes that the proportion of women employed part-time is higher than the proportion of men.

Table 2: Part-Time Jobs - Percent of all Jobs

\begin{tabular}{l|ccc|ccc|ccc|ccc}
\hline \hline & \multicolumn{9}{|c}{ All } & \multicolumn{4}{c}{ Age 15-24 } & \multicolumn{4}{c}{ Age $>54$} \\
Country & Men & Women & Share & Men & Women & Share & Men & Women & Share & Men & Women & Share \\
\hline \multirow{3}{*}{ France } & $(1)$ & $(2)$ & $(3)$ & $(4)$ & $(5)$ & $(6)$ & $(7)$ & $(10)$ & $(11)$ & $(12)$ & $(13)$ & $(14)$ \\
Netherlands & 5.2 & 24.1 & 79.5 & 9.7 & 26.6 & 67.6 & 4.1 & 23 & 82.7 & 10.6 & 32.3 & 71 \\
USA & 14.7 & 58.8 & 75.4 & 49.3 & 60.7 & 53.5 & 5.9 & 57.1 & 88.3 & 26.8 & 71 & 56.8 \\
\hline \hline
\end{tabular}

Notes: Data for 2002. Columns labelled 'Share' contain the share of women of total part-time work. Other columns contain the proportion of part-time work

Source: OECD Statistical database.

The evolution of the proportion of part-time jobs over time is also instructive. Over the last twenty years the Netherlands always have had the greatest proportion of part-time work in the whole population. This is mostly explained by the fact that part-time work is very prevalent for women in that country. ${ }^{7}$ The importance of part-time work among women is true for other countries as well. Finally, except in the Netherlands, there is little change in part-time employment for the $25-54$ age group within the whole population. In the Netherlands, the proportion of part-time jobs has increased a lot for that category. ${ }^{8}$

\subsection{Labor Market Institutions and Income Taxation}

Countries differ greatly in terms of legislation on unions, wage setting, hours worked, and taxation. Some of these facts are reviewed. In particular, given that the model described below makes use of $(i)$ varying average time between recontracting possibilities, $(i i)$ choice of hours, (iii) taxation differences, and that, in addition, it is closely linked to other labor market institutions, the situation in the countries of interest is reviewed. It is argued that

\footnotetext{
${ }^{5}$ To a large extent, part-time work is chosen in accordance with the preferences of workers. For instance, $78 \%$ of working part-time women in the Netherlands do not want to work full-time. See Nickell and van Ours (2000).

${ }^{6}$ In France and in the Netherlands, women of age 55 and more account for most of women part-time, with women in the 15-24 age category coming a close second.

${ }^{7}$ See Pissarides, Garibaldi, Olivetti, Petrongolo, and Wasmer (2005) for more on this topic.

${ }^{8}$ All this is documented in Figures 7, 8, and 9 in the Appendix.
} 
Table 3: Labor market institutions

\begin{tabular}{lccc}
\hline \hline & France & Netherlands & United States \\
Union Density & 9.7 & 23.2 & $12.8^{\mathrm{a}}$ \\
Wage Bargaining & $\mathbf{9 5}$ & 80 & $\mathbf{1 4}$ \\
Centralization & 2 & 3 & 1 \\
Coordination & 2 & $\mathbf{4}$ & 1 \\
Bargaining frequency (years) & 1.5 & $\mathbf{0 . 5}$ & No pattern \\
Weekly normal hour limits & $\mathbf{3 5}-\mathbf{3 9} \mathbf{b}^{\mathrm{b}}$ & $40^{\mathrm{c}}$ & $40^{\mathrm{d}}$ \\
Maximum legal weekly hours $^{\mathrm{e}}$ & $41-47$ & $41-47$ & No limit \\
\hline \hline
\end{tabular}

Notes: Trade Union density: data from administrative sources except where stated. Data for 2000. Wage bargaining: percentage of employees covered by collective agreements as a percentage of the total number of employees. Data for 2000. Centralization and coordination: index from 1 (least centralization and coordination) to 5 (highest level of centralization and coordination). Data for 2000.

Source: OECD Statistical database (wage bargaining and union density), OECD Employment Outlook 2004. (centralization and coordination), Délégation du Sénat pour l'Union Européenne (1998) (bargaining frequencies), and McCann (2005) (restrictions on hours worked).

${ }^{\text {a }}$ Survey. $\quad{ }^{\text {b }}$ Labour Code, Decree No. 2002-1257, 2001. $\quad{ }^{\mathrm{c}}$ Working Time Decree,

1995. $\quad$ d Fair Labor Standards Act, $1938 . \quad{ }^{\mathrm{e}}$ Includes extra time.

the US is the country with the most flexible labor market characteristics and the lowest level of income taxation and that France is the opposite extreme. It is also shown that the Netherlands have level of income taxation similar to that in France but have implemented changes in the labor market legislation which have greatly increased the flexibility of the labor market.

\subsubsection{Labor Market Settings}

Table 3 displays data on union density, wage bargaining through collective agreements, indexes of centralization and coordination between unions, employers, and governments, frequencies of bargaining, and restrictions on hours worked for the same set of countries.

The US is a country characterized by the highest level of flexibility on the labor market. It has the lowest level of wage bargaining (collective bargaining coverage of $18 \%$ ) among the three countries. Bargaining takes place exclusively at the firm level and with no particular pattern in terms of bargaining frequency. The situation is also very flexible regarding choices of hours worked. The normal work week in the US is similar to the one in the other two countries but there is no legal maximum number of weekly hours. In addition, evidence from weekly hour bands indicates that most people work full time in the US, and Americans tend to work long weeks (see Figure 10 in the Appendix). 
France and the Netherlands have a collective bargaining coverage greater than $80 \%$. This is true even though union density is relatively small (less than 20\% in France and between $20 \%$ and $30 \%$ in the Netherlands). Wages are defined at the national level but within sectors in the Netherlands. Wage negotiation takes place within firms in France, but is sometimes framed by sectoral agreements. Negotiations take place every year and a half in France and twice a year in the Netherlands. The legal maximum number of weekly hours, which includes extra-time, is limited in both France and in the Netherlands. Data on weekly hour bands underline the fact that most people work full time in France, as is the case in the US, that Americans tend to work longer weeks, and that the population is spread out in most bands in the Netherlands (see Figure 10 in the Appendix).

A part from the frequency of negotiations, what distinguishes the Netherlands from France is the high level of centralization and of coordination between unions, employers and the government. This leads the Netherlands to have a higher degree of flexibility of the labor market. In that country, since the early 1980's, there have been important discussions between the government, the unions, and the employers which have led to a great level of coordination between all social partners. In 1982, the Wassenaar agreement marked a change in relations between Dutch unions, employers and the government. Unions agreed to more flexibility in wage setting and hours worked, and to give up resistance to part-time work. (See Nickell and van Ours (2000) for more details.) The Wassenaar agreement, as well as others that followed, have lead the unions to repeatedly accept greater flexibility in terms of choices of the working day, and to remove obstacles to part-time work. This process of improvement of flexibility is still taking place. For instance, the part-time Employment Act, passed by the lower house of the Dutch Parliament in February 2000, awards employees the right to increase or reduce their working hours.

To summarize, the US is characterized by a high level of decentralization, a low level of coordination between social partners and a relatively low level of coverage. Within Europe, one can distinguish France from the Netherlands. In France, negotiations are decentralized and not frequent, union density is small and coordination between social partners is small, but collective bargaining coverage is high. The Netherlands are characterized by a higher degree of centralization, more coordination and a high collective bargaining coverage with more frequent negotiations. The combination of these three elements greatly improves the 
flexibility of the Dutch labor market.

\subsubsection{Labor Income Taxes}

Labor income taxation is likely to influence labor/leisure decisions of households. Prescott (2003) discusses the effects of effective marginal tax rates on labor income in Germany, France, Italy, and the US. He shows that differences in tax rates account for most of the differences in labor supply in these countries (except Italy).

Effective income taxation levels are presented in Table 4. This table clearly shows that the labor income tax is much higher in France and in the Netherlands than in the US. Income taxes increase over time in all countries, and to a larger extent in the Netherlands and in France.

Table 4: Effective Tax Rates on Labor Income, 1965-1991

\begin{tabular}{ccccccc}
\hline \hline Countries & $1965-1970$ & $1971-1975$ & $1976-1980$ & $1981-1985$ & $1986-1990$ & $1991-1996$ \\
\hline France & 33.9 & 33.0 & 37.9 & 42.4 & 46.2 & 54.0 \\
Netherlands & 36.1 & 42.7 & 47.1 & 50.1 & 51.8 & - \\
USA & 20.1 & 23.0 & 26.1 & 28.3 & 28.6 & 27.7 \\
\hline \hline
\end{tabular}

Notes: Mendoza-Razin-Tesar effective tax rates updates through 1996 calculated using the method proposed in Mendoza, Razin, and Tesar (1994)

\section{The Model}

Ours is a quantitative two-sided search model with ex-ante heterogeneity in both worker and firm types and idiosyncratic shocks, as proposed in Danthine (2005), extended to include labor/leisure choices and bargaining frictions. Time is discrete. The economy is inhabited by heterogeneous and infinitely-lived workers and firms. A worker's productivity level is labelled by $z \in Z=\left\{z_{1}, \ldots, z_{N}\right\}$, while a firm's productivity is denoted by $x \in X=\left\{x_{1}, \ldots, x_{M}\right\}$. A worker of type $z_{k}$ evolves to type $z_{l}$ with transition probability $Z(l \mid k)$. Similarly, a firm's productivity evolves from $x_{i}$ to $x_{j}$ following the transition probability $X(j \mid i)$. When searching for a worker, a firm holding a vacancy meets a worker of type $z_{k}$ with probability $\Omega_{k}$. Similarly, an unemployed worker meets a firm of type $x_{i}$ with probability $\Phi_{i}$. A newly matched pair $i k$ bargains over the hourly wage $w_{i k}$ and the number of per period hours $h_{i k}$. If the two find a mutually agreeable arrangement, they produce using production function $F_{i k}\left(h_{i k}\right)$. In 
that case, define the indicator function $I_{i k}=1$. Otherwise, they lose a productive period, have to search once more next period and $I_{i k}=0$. A previously matched pair composed of types $i k$, with previous contract $(w, h)$, evolves to $j l$ with probability $X(j \mid i) Z(l \mid k)$. With probability $\pi$, the pair can bargain over a new contract. If the two parties manage to agree on new terms, $I_{j l}=1$ and the new contract is $\left(w_{j l}, h_{j l}\right)$. Otherwise they lose a period, start searching again, and $I_{j l}=0$. With probability $(1-\pi)$, they are not allowed to recontract. In that case, either they agree to remain together, allowing one to define an indicator function $J_{j l}(w, h)=1$. If either member (or both) find that searching grants a higher value, they separate and $J_{j l}(w, h)=0$.

\subsection{Firms}

A firm can be in any of three situations at the beginning of a period: matched with a worker and allowed to bargain again; matched with a worker and not allowed to bargain, in which case the worker and the firm must choose whether to remain matched at the previously set conditions or to split; vacant and in negotiation with a worker. Let $V_{i}$ be the value for a firm of type $i$ of remaining vacant and $P_{i k}$ the value of a new contract for a firm of type $i$ matched with a worker of type $k$. Finally, let $L_{i k}\left(w_{i k}, h_{i k}\right)$ be the value for a firm of type $i$ matched with a worker of type $k$ of producing under a previous contract $h_{i k}$. Then,

$$
\begin{aligned}
P_{i k}=F_{i k}\left(h_{i k}\right)-w_{i k} h_{i k} & +\beta \sum_{j} \sum_{l} X(j \mid i) Z(l \mid k)\left[\pi\left(I_{j l} P_{j l}+\left(1-I_{j l}\right) V_{j}\right)\right. \\
& \left.+(1-\pi)\left(J_{j l}\left(w_{i k}, h_{i k}\right) L_{j l}\left(w_{i k}, h_{i k}\right)+\left(1-J_{j l}\left(w_{i k}, h_{i k}\right)\right) V_{j}\right)\right] .
\end{aligned}
$$

Although complicated at first sight, this expression is straightforward. $F_{i k}\left(h_{i k}\right)-w_{i k} h_{i k}$ is just the net profit of the firm over the period. The pair $i k$ then evolves to $j l$ with probability $X(j \mid i) Z(l \mid k)$; with probability $\pi$, it can renegotiate and either decide to pursue their partnership $\left(I_{j l}=1\right)$ or not. With probability $(1-\pi)$, the pair cannot renegotiate, and must decide whether to remain in partnership at the old contract $\left(J_{j l}\left(w_{i k}, h_{i k}\right)=1\right)$ or not. The value of remaining vacant is simply given by

$$
V_{i}=\beta \sum_{j} \sum_{l} X(j \mid i) \Omega_{l}\left(I_{j l} P_{j l}+\left(1-I_{j l}\right) V_{j}\right)
$$


where $X(j \mid i) \Omega_{l}$ is the probability of evolving from type $i$ to type $j$ and to meet a worker of type $l$. Notice that a newly matched pair is always allowed to bargain. Finally,

$$
\begin{array}{rl}
L_{i k}(w, h)=F_{i k}(h)-w h+\beta \sum_{j} \sum_{l} & X(j \mid i) Z(l \mid k)\left[\pi\left(I_{j l} P_{j l}+\left(1-I_{j l}\right) V_{j}\right)\right. \\
& \left.+(1-\pi)\left(J_{j l}(w, h) L_{j l}(w, h)+\left(1-J_{j l}(w, h)\right) V_{j}\right)\right] .
\end{array}
$$

The continuation part of this expression is identical to that in (1). The first part is just the net period profits given current types and past hours and wages.

\subsection{Workers}

A worker can be in the same three situations, and the expressions for workers' value functions are very similar to those of the firm. Denote the value of being employed at newly negotiated terms by $E$, the value of being employed at formerly negotiated terms by $T$, and the value of being unemployed by $U$. The value for a type $k$ worker of being employed by a type $i$ firm is given by

$$
\begin{aligned}
E_{i k}=u\left((1-\tau) w_{i k} h_{i k}, h_{i k}\right) & +\beta \sum_{j} \sum_{l} X(j \mid i) Z(l \mid k)\left[\pi\left(I_{j l} E_{j l}+\left(1-I_{j l}\right) U_{l}\right)\right. \\
& \left.+(1-\pi)\left(J_{j l}\left(w_{i k}, h_{i k}\right) T_{j l}\left(w_{i k}, h_{i k}\right)+\left(1-J_{j l}\left(w_{i k}, h_{i k}\right)\right) U_{l}\right)\right] .
\end{aligned}
$$

It looks very much like equation (1), the difference being that workers have possibly non-linear utility $u(\cdot)$ and may be taxed at rate $\tau$. The value of being unemployed is just

$$
U_{k}=u((1-\tau) b+s, 0)+\beta \sum_{j} \sum_{l} Z(l \mid k) \Phi_{j}\left(I_{j l} E_{j l}+\left(1-I_{j l}\right) U_{l}\right)
$$

where $b$ is unemployment benefits and $s$ is home ("self") production. Finally, being employed by a type $i$ firm but at past hours $h$ and wage $w$ yields

$$
\begin{aligned}
T_{i k}(w, h)=u((1-\tau) w h, h)+\beta \sum_{j} & \sum_{l} X(j \mid i) Z(l \mid k)\left[\pi\left(I_{j l} E_{j l}+\left(1-I_{j l}\right) U_{l}\right)\right. \\
& \left.+(1-\pi)\left(J_{j l}(w, h) T_{j l}(w, h)+\left(1-J_{j l}(w, h)\right) U_{l}\right)\right] .
\end{aligned}
$$

\subsection{Nash Bargaining}

We now define two indicator functions, $I$ and $J$. The first follows from the Nash Bargaining problem. A firm of type $i$ and a worker of type $k$ choose a wage $w_{i k}$ and hours $h_{i k}$ to maximize 
the product of their surpluses under the constraint that both surpluses must be non-negative:

$$
\begin{array}{r}
\max _{h, w}\left[P_{i k}(w, h)-V_{i}\right] \quad \times \quad\left[E_{i k}(w, h)-U_{k}\right], \\
\text { st. } \\
P_{i k}(w, h) \geqslant V_{i} \text { and } \quad E_{i k}(w, h) \geqslant U_{k} .
\end{array}
$$

If a solution to this problem exists, then $I_{i k}=1$, otherwise $I_{i k}=0$. In similar fashion, $J_{i k}(w, h)=1$ if, at the terms of the last negotiated contract $(h, w)$, both the firm and the worker have a positive surplus, so that $L_{i k}(w, h) \geqslant V_{i}$ and $T_{i k}(w, h) \geqslant U_{k}$. Otherwise, if either or both prefer searching again, $J_{i k}(w, h)=0$. With the existing distribution of workers and firms and with the newly defined indicator function, it is possible to update the distributions.

\subsection{Updating the Distributions}

Updating the probability of meeting a worker or a firm of a certain type involves counting. Let $M_{i k o p}^{b}$ be the measure of pairs of type $i k$ who in the previous period were allowed to bargain and chose a contract $\left(w_{o p}, h_{o p}\right) .{ }^{9}$ Similarly, let $M_{i k o p}^{n}$ be the measure of pairs of type $i k$ who did not bargain in the previous period, had a previously agreed upon contract $\left(w_{o p}, h_{o p}\right)$, and remained together. Then $\sum_{o} \sum_{p}\left(M_{i k o p}^{b}+M_{i k o p}^{n}\right)$ is the measure of $i k$ pairs who were matched in the previous period. Of these worker-firm pairs, a proportion $\pi$ are allowed to renegotiate. In addition, there is a measure $\Phi_{i} \Omega_{k} N$ of $i k$ pairs who meet in the market. If they can find a mutually agreeable contract $\left(w_{i k}, h_{i k}\right)$, then they engage in production $\left(I_{i k}=1\right)$. Any pair consisting of types $i$ and $k$ evolves to types $j$ and $l$ with probability $X(j \mid i) Z(l \mid k)$. Hence, at the beginning of the next period, the measure of $j l$ pairs who were matched with contract $\left(w_{i k}, h_{i k}\right)$ is given by:

$$
M_{j l i k}^{b^{\prime}}=\left[\left(\sum_{o} \sum_{p} M_{i k o p}^{b}+M_{i k o p}^{n}\right) \pi+\Phi_{i} \Omega_{k} N\right] I_{i k} X(j \mid i) Z(l \mid k) .
$$

In somewhat similar fashion, multiplying the measure of pairs of type $i k$ who had contract $\left(w_{o p}, h_{o p}\right)$ by $(1-\pi)$ yields the measure of $i k$ firms who cannot renegotiate and have to decide whether or not to continue producing at the past contractual terms. If they decide it is worth to maintain their relationship, $J_{i k o p}=1$. The probability that they evolve to $j l$ is given by $X(j \mid i) Z(l \mid k)$. Summing over all possible $i k$ 's leads to the measure of $j l$ pairs who cannot

\footnotetext{
${ }^{9}$ In fact, this implies they were of type $o p$ in the previous period.
} 
rebargain and carry over choice $h$ from this period to the next:

$$
M_{j l o p}^{n^{\prime}}=\sum_{i} \sum_{k}\left[M_{i k o p}^{b}+M_{i k o p}^{n}\right](1-\pi) J_{i k o p} X(j \mid i) Z(l \mid k) .
$$

The probability of meeting a worker of type $k$ is just the measure of unmatched workers of that type divided by the total number of unmatched workers. To obtain this, define $A_{j l}$ as the measure of $j l$ pairs who met in the previous period and did not find an agreeable contract, given that they were allowed to (re-)bargain. Similarly, define $B_{j l}$ to be the measure of pairs $j l$ who decided not to produce last period given that they could not renegotiate. These are given by

$$
A_{j l}=\sum_{i} \sum_{k}\left[\sum_{o} \sum_{p}\left(M_{i k o p}^{b}+M_{i k o p}^{n}\right) \pi+\Phi_{i} \Omega_{k} N\right]\left(1-I_{i k}\right) X(j \mid i) Z(l \mid k),
$$

and

$$
B_{j l}=\sum_{i} \sum_{k}\left[\sum_{o} \sum_{p}\left(M_{i k o p}^{b}+M_{i k o p}^{n}(1-\pi)\left(1-J_{i k o p}\right)\right)\right] X(j \mid i) Z(l \mid k) .
$$

It should be clear that the measure of unmatched workers or firms is given by the double sum

$$
N^{\prime}=\sum_{l} \sum_{j}\left(A_{j l}+B_{j l}\right)
$$

Summing $A_{j l}+B_{j l}$, for each firm type, across worker types and dividing by $N^{\prime}$ yields the distribution of vacancy types. The distribution of unemployed is obtained in similar fashion. Formally,

$$
\Phi_{j}^{\prime}=\frac{\sum_{l}\left(A_{j l}+B_{j l}\right)}{N^{\prime}}
$$

and

$$
\Omega_{l}^{\prime}=\frac{\sum_{j}\left(A_{j l}+B_{j l}\right)}{N^{\prime}}
$$

\subsection{Stationary Equilibrium}

A stationary equilibrium is a set of value functions $E, P, U, V, L, T$, distributional functions $\Phi, \Omega, M^{b}, M^{n}, N$ and indicator functions $I, J$ such that $E, P, U, V, L, T$ satisfy equations (1)(6), $I, J$ are defined by (7), and the distributions are stationary. 


\section{Results}

To evaluate the model, three steps are taken. First, functional forms are given and the parameters are chosen. Second, the properties of the numerical equilibrium and their sensitivity to parameter changes are discussed. Third, changes in income taxation coupled with changes in the probability of recontracting are introduced. This allows us to use the model to rationalize the differences in the economic performances of the United States, France, and the Netherlands documented above.

\subsection{Parametrization}

Functional forms for the production function, for individual preferences and for the idiosyncratic shocks must be specified. The production function is assumed to be a Cobb-Douglas with $\alpha=0.4$ and $\mu=0.8$, which implies diminishing returns to hours worked:

$$
F_{i k}(h)=h^{\mu}\left(x_{i}^{\alpha} z_{k}^{1-\alpha}\right)
$$

The utility function is assumed to be

$$
u(c, h)=\frac{c^{(1-\sigma)}}{1-\sigma}-a \frac{h^{\nu}}{\nu} .
$$

Preference parameters, like the technology parameters, are set following existing literature standards. The parameter of risk aversion, $\sigma$, is set to be 0.4 . The parameter that fixes the level of consumption-leisure elasticity is set to $a=2.5$ in the benchmark parametrization. Similarly, $\nu$ is set to 1 (hours enter linearly in the utility), as in Cooley and Hansen (1995). ${ }^{10}$

The rate of time preference is set to $\beta=0.95$. This implies that the length of the period in the model is approximatively a year. The average time between contracts is not something readily available from the data. According to the French Senate, the average time between recontracting varies between two and eight quarters in European countries (see Délégation du Sénat pour l'Union Européenne (1998)). Counting one year for a period in the model implies that the average time is about two years and four months for $\pi=0.3$, one year for $\pi=0.5$, and it is about 4 months when $\pi=0.7$. Home production is only introduced to prevent a log-utility specification from giving a highly negative utility, and it is set to a minimal level of 0.1. The preference and technology parameters used in the benchmark model

\footnotetext{
${ }^{10}$ The results are checked to be robust to variations in the parameters $\alpha, \mu, \sigma, a$, and $\nu$.
} 
are summarized in Table 5. Workers and firms have to choose one of four possible work days: $h \in\{0.25,0.5,0.75,1\}$.

Table 5: Model Parameters

\begin{tabular}{lcc}
\hline \hline Parameter & Meaning & Value \\
\hline$\beta$ & discount factor & 0.95 \\
$\sigma$ & risk aversion & 0.4 \\
$\nu$ & labor/leisure parameter & 1 \\
$a$ & aversion to work & 2.5 \\
$\alpha$ & coefficient on firm type (production function) & 0.4 \\
$\mu$ & coefficient on hours (production function) & 0.8 \\
$s$ & home production & 0.1 \\
$\pi$ & recontracting probability & varies \\
\hline \hline
\end{tabular}

The idiosyncratic shocks are set in the following way. Worker types are interpreted to correspond to education levels. It is assumed that there are ten different types of workers in the model. More precisely, the lower two types are labelled "less than high school", the next three are labelled "high school graduates" the next three are labelled "college grads" and finally the last two types represent postgraduates. The Markov matrix is then chosen so that (i) the distribution of diplomas in the model is roughly similar to that in the data, $(i i)$ the movement between diplomas is not 'too' large. Ideally, a firm's type could be interpreted as its productivity. Unfortunately, data on firm productivity is hard to come by. There is some data available on the job skill requirement, in terms of education, of posted vacancies. Here, it is assumed that the type of a firm corresponds to its job skill requirement. The idiosyncratic shocks to the firms are then calibrated so that the distribution of job skill requirements among all firms in the model corresponds to the distribution, among vacancies, in the 1985 PSID (as reported by Handel (2000)). ${ }^{11}$ The model distributions as well as those for the US (BLS 2001 (workers) and PSID 1985 (firms)) can be found in Table 6.

In the next section, the effects of changes in the probability of recontracting, as well as changes in labor taxation, are analyzed.

\footnotetext{
${ }^{11}$ Results are checked to be robust to changes in the parametrization of the idiosyncratic shocks.
} 
Table 6: Distribution of Education Levels and Job Skill Requirements

\begin{tabular}{lcc||cc}
\hline \hline \multirow{2}{*}{ Education } & \multicolumn{2}{c}{ Worker } & \multicolumn{2}{c}{ Firm } \\
& Model & USA & Model & USA \\
\hline$<$ HS & $10 \%$ & $10.1 \%$ & $10 \%$ & $13.2 \%$ \\
HS and some college & $56 \%$ & $59.6 \%$ & $56 \%$ & $56.3 \%$ \\
college & $24 \%$ & $20.0 \%$ & $24 \%$ & $23.4 \%$ \\
$>$ college & $10 \%$ & $10.2 \%$ & $10 \%$ & $7.1 \%$ \\
\hline \hline
\end{tabular}

Source: BLS 2001 (workers) and PSID 1985 (firms).

\subsection{Contracts, Taxes and Labor Market Performance}

The behavior of the model when the probability of recontracting changes, as well as when taxation varies, is examined. The results are then evaluated in light of the data discussed in Section 2 .

\subsubsection{Effects of Flexibility in Contracting}

What happens, in this economy, when the probability of recontracting increases? Figure 3 plots GDP per capita, GDP per worker and GDP per hours worked in the benchmark economy. ${ }^{12}$ When $\pi<0.7$, GDP per capita increases with $\pi$. GDP per worker closely follows. Conversely, GDP per hours worked decreases. Once $\pi>0.7$, the trend flattens out: GDP per capita and GDP per hours worked now remain relatively constant as a function of $\pi$.

Taking a look at Figure 4 helps understand what is happening. In that figure, employment and the share of part-time jobs are plotted against $\pi \cdot{ }^{13}$ As $\pi$ increases, both the proportion of part-time jobs and employment increase at first but then flatten out. Until $\pi=0.4$, however, the share of part-time jobs increases faster than employment. This implies that employment is increasing at a faster rate than the total number of hours worked. Hence, GDP per capita increases and GDP per hour decreases. This is the case until $\pi=0.6$ at which point both employment and the share of part-time jobs become almost unaffected by further increase in flexibility. At that point $(\pi=0.6)$, GDP per capita and GDP per hour flatten out.

\footnotetext{
${ }^{12}$ GDP per capita and per worker are in right axis units in Figure 3, while GDP per hour is in terms of the left axis.

${ }^{13}$ The share of part-time jobs in all jobs is depicted against the left axis, employment against the right.
} 
Figure 3: GDP's and recontracting probabilities

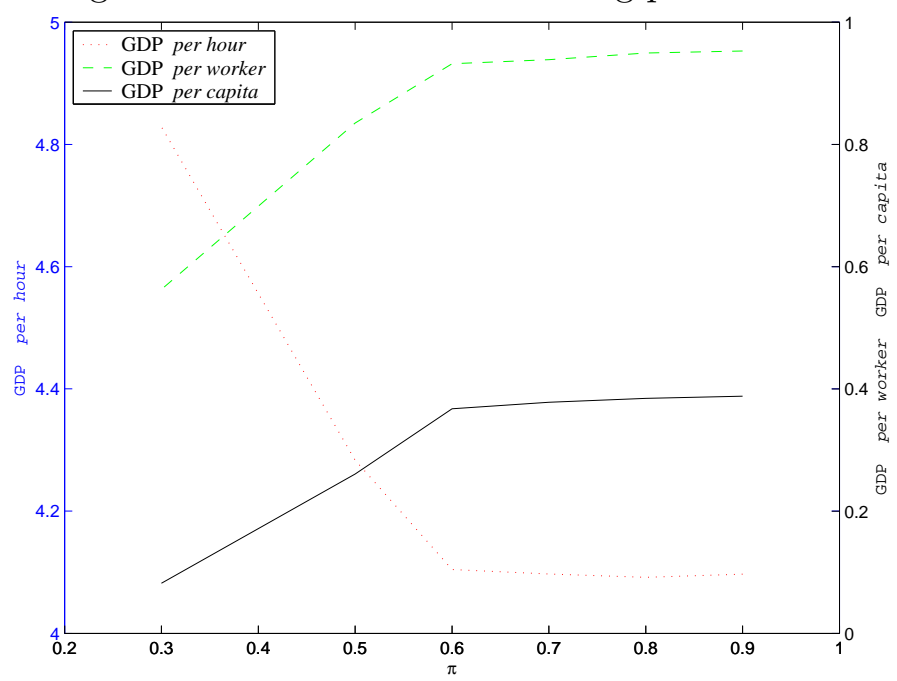

Figure 4: Employment and part-time jobs

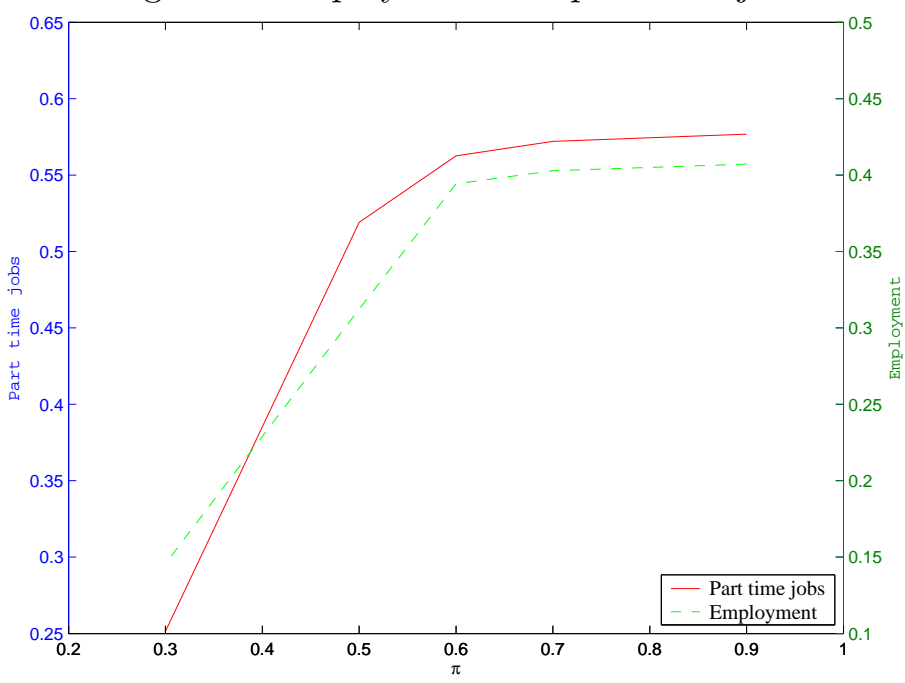


Which pairs are affected by a change in the recontracting probability? The answer is obtained from Figure 5, where the hour choices made by worker and firm types for three different values of $\pi-0.3,0.5$ and 0.7 - are depicted. ${ }^{14}$ Firms are represented on the y-axis with firm type increasing from bottom to top. Workers are on the x-axis and increase in type from left to right. A black square represents a situation where the corresponding pair does not match. As the color lightens, the percentage of daily time devoted to work increases. ${ }^{15}$ For instance, if $\pi=0.3$, a worker of type 6 and a firm of type 7 decide to use 0.5 of a full day for production. Generally, as flexibility increases, both the white area, representing pairs engaged in full-time jobs, and the grey area, representing part-time relationships, increase, while the area in which pairs do not match (in black) decreases.

Going into more details, when $\pi$ increases from 0.3 to 0.5 , a number of pairs who do not match when $\pi=0.3$ produce when $\pi=0.5$. Workers of type 4 start working a quarter-time with firms of type 9 and 10. Workers of type 5 start working a quarter day with firms of type 7 and half-time with firms of type 8. Workers of type 6 now work half-time in firms of type 6 , workers of type 7 work three-quarters of the day in firms of type 5 , and workers of type 9 now work full time in firms of type 4 . Moving from the intermediate case $(\pi=0.5)$ to the more flexible case $(\pi=0.7)$, workers of type 4 (respectively, 5,6 , and 8) start working with firms of type 8 (respectively, 6, 5, and 4) for a quarter of the day (respectively quarter, half, and three-quarter of the day). Workers of type 10 start working full-time with firms of type 3. In addition, workers of type 5 who would work half-time in the intermediate case now work quarter-time. Finally, workers of type 8 increase the length of their work-day in firms of type 5 from three-quarter to full time.

The intuition of what is going on is the following. In an economy with flexible wages and no leisure-labor decision, a number of pairs who cannot produce more together than individually decide to match anyway, while others do not. If the pair's joint evolution makes it likely enough to get better in the next period, and if this evolution is more likely than meeting a better partner in the future, the pair decides to lock up a match. The possibility of choosing part-time work makes it easier to lock-up a match. Once rigidities are introduced, and hours cannot be rebargained for sure in the future, locking a match with a small workday is not as profitable. This will deter some pairs from locking-up a partnership. As flexibility

\footnotetext{
${ }^{14}$ It is important to remember that the measure of each pair in these figures differ.

${ }^{15} h$ goes from 0.25 of the available time to 1.0 via 0.5 and 0.75 .
} 
Figure 5: Hour choices

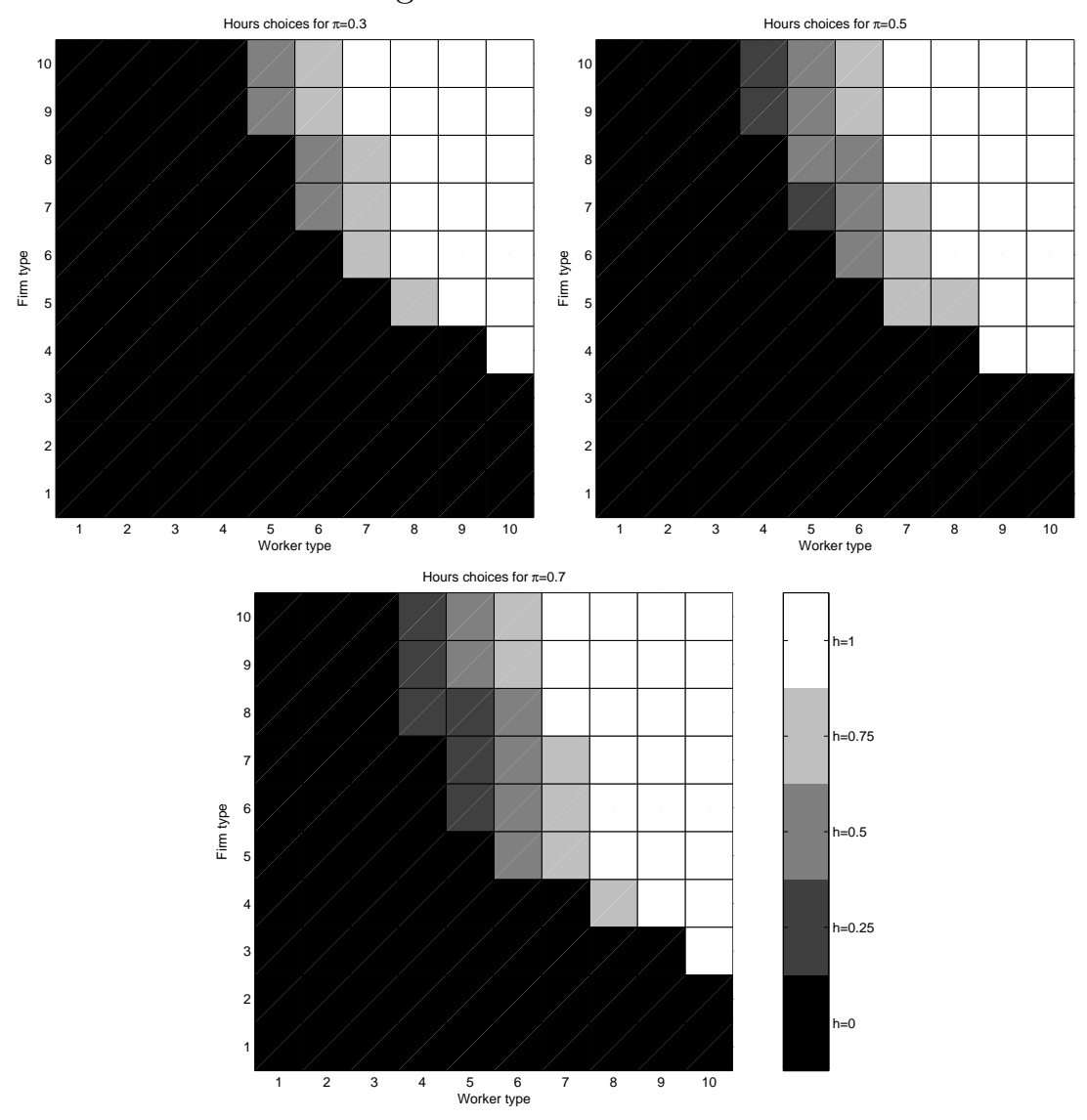


increases, more and more pairs on the margin will go for part-time work. Hence employment increases and the proportion of part-time work increases, with the result that GDP per capita and the number of hours worked increase.

Are these results robust? Changes in the parameters of the production function, $\mu$ and $\alpha$, do not qualitatively modify the results. As $\mu$ gets smaller, the differences between the economies with different degrees of rigidity become smaller. This is due to the diminishing marginal return of hours worked. Changes in $\alpha$ mostly modify the matching sets and therefore the unemployment rate. Variations in the idiosyncratic shocks have no qualitative effects on the results and small change in those shocks have no quantitatively significant effects either. The parameters of the utility function are closely linked. Increasing risk-aversion $\sigma$, for instance, while decreasing $a$ and/or increasing $\nu$, leaves the results qualitatively unchanged and yields very small quantitative variations. Changing one of these parameters while leaving the others constant mostly affect the level of flexibility, measured by $\pi$, at which an inflection point is observed in the GDP curves. For instance, as the parameter of risk aversion $\sigma$ and the parameter $a$ increase, the level of $\pi$ at which GDP per capita starts to flatten decreases, and as $\nu$ increases, that level of $\pi$ increases. If risk aversion increases a lot without changes in $a$ or $\nu$, it is even possible to obtain a situation in which a high level of rigidity leads to a high level of production. The reason is that working is very costly for workers, who thus wish to work only in the best firms. There is then a very low level of employment. Increasing flexibility slightly rises the employment level, and this has a positive effect on GDP per capita, but lowers the level of sorting, and this has a negative effect on GDP per capita. With a low level of employment, the second effect dominates.

\subsubsection{Effect of Labor Income Taxation}

As documented in Section 2, labor income taxation varies across countries. In general, the level of income taxation is much lower in the US than in Europe. It is possible to explain the different effects of increased taxation on economies with high or low rigidity. Income taxation distorts the marginal revenue of an extra hour of work. Hence, when tax increases, the workers wish to work less. Rigidity in both wage setting and hour choice decreases the long-term benefits of engaging in a part-time professional relationship. The result is that many potential part-time situations are converted in non-employment. As flexibility increases, the long-term cost associated with part-time work decreases, and the share of 
part-time work increases with taxation.

Table 7 displays GDP per capita, per worker and per hour, employment (E) and the proportion of part-time jobs (Part/Tot) for three levels of taxation and for three economies differing in their level of rigidity $(\pi=0.3,0.5,0.7)$. Call the first economy "rigid", the second "intermediate" and the third "flexible". All variables are normalized in terms of the situation in the flexible economy with no labor income taxation. This allows a comparison of the magnitude of the effects in the three economies. In all three economies, increasing taxation has the effect of decreasing GDP per capita, decreasing employment and increasing GDP per hour. The effects on the proportion of part-time jobs differ, however. Part-time jobs disappear in the economy with the highest rigidity when taxes are raised from 0 to 0.3 , but the share of part-time jobs increases when taxes are raised from 0.3 to 0.5 . This increase is largely due to the very low level of employment. It would be much smaller, and could even disappear, in a parametrization in which employment remains higher. The share of parttime jobs increases a lot in the economy with low rigidity. In the intermediate economy, the proportion of part-time jobs increases but less than in the most flexible case. As expected, employment decreases less with taxation when the economy is more flexible.

Table 7: Effect of variations in labor income tax

\begin{tabular}{lccc|ccc|ccc}
\hline \hline & \multicolumn{3}{c}{$\pi=0.3$} & \multicolumn{3}{c}{$\pi=0.5$} & \multicolumn{3}{c}{$\pi=0.7$} \\
$\tau$ & 0.0 & 0.3 & 0.5 & 0.0 & 0.3 & 0.5 & 0.0 & 0.3 & 0.5 \\
\hline GDP pc & 0.85 & 0.48 & 0.26 & 0.95 & 0.64 & 0.45 & 1.00 & 0.69 & 0.55 \\
GDP pwk & 0.58 & 0.16 & 0.04 & 0.83 & 0.36 & 0.19 & 1.00 & 0.47 & 0.33 \\
GDP ph & 1.07 & 1.31 & 1.53 & 1.02 & 1.21 & 1.37 & 1.00 & 1.18 & 1.28 \\
E & 0.68 & 0.32 & 0.17 & 0.87 & 0.56 & 0.42 & 1.00 & 0.67 & 0.60 \\
Part/Tot & 0.48 & 0.47 & 0.87 & 0.80 & 1.14 & 1.59 & 1.00 & 1.36 & 1.81 \\
\hline \hline
\end{tabular}

Notes: All variables are normalized by the values for parameters $\pi=0.7$ and $\tau=0.0$. E is employment, Part/Tot is part-time jobs divided by all jobs.

The effect of an increase in the labor income tax on pairwise hour choices in the economy with $\pi=0.5$ is depicted in Figure 6. Clearly, many viable pairs in the economy with no taxation, the majority of them engaged in part-time contracts, are driven out by taxation. At the same time, a number of pairs who produce full-time when taxation is low reduce their work-days. It is then clear that there is a possibility that the proportion of part-time jobs increase or decrease as taxation increases, and that this depends on the total level of employment. 
Figure 6: Hour choices

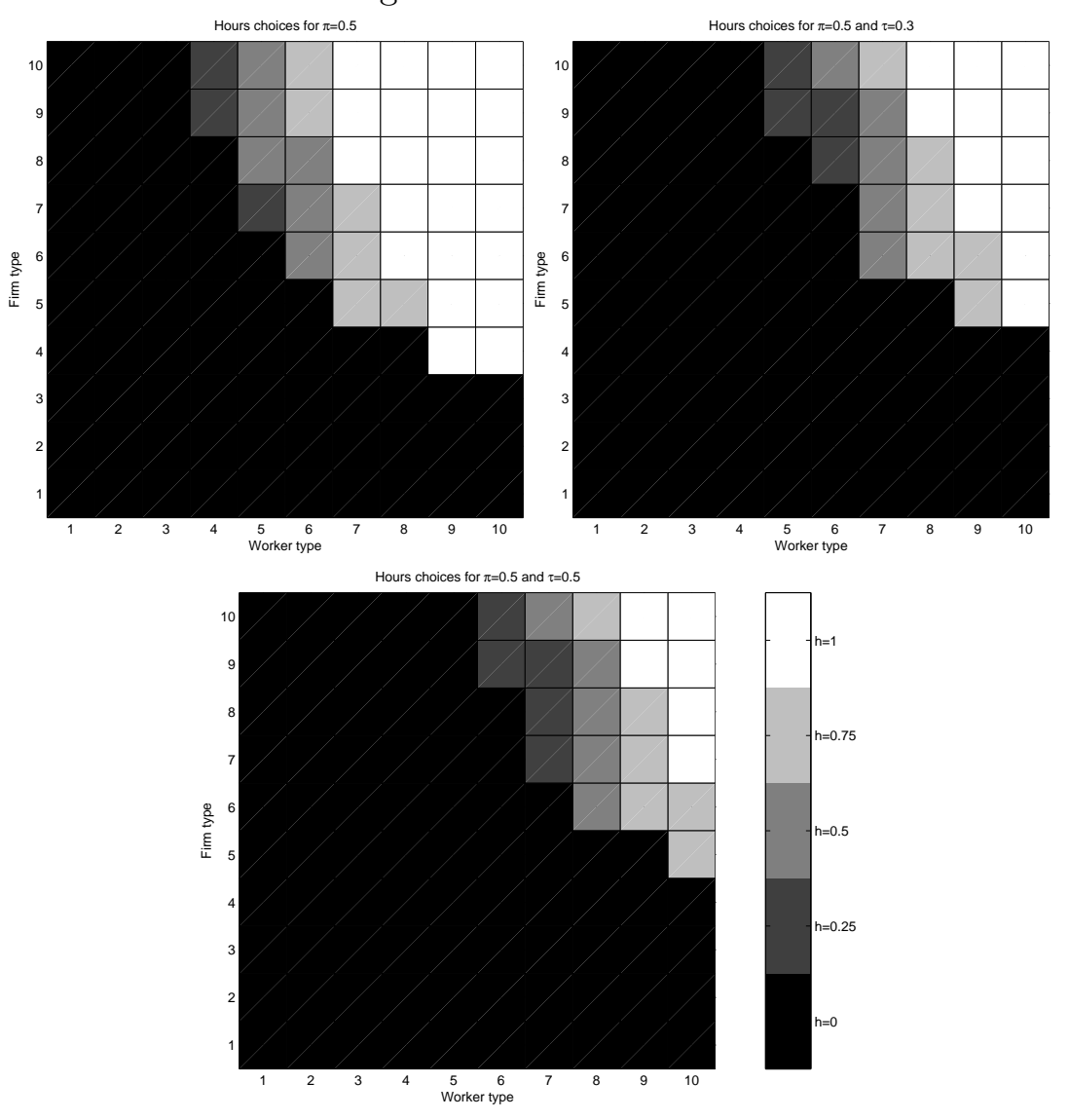




\subsubsection{Can the Model Explain Cross-country Differences?}

It is useful to summarize briefly the results described above. Starting from a situation where the probability of recontracting is low, an increase in that probability increases employment and GDP per capita, and decreases GDP per hour. When $\pi>0.7$, these measures of GDP flatten out. In addition, as $\pi$ increases, the proportion of part-time work in the economy keeps increasing. When looking at France, the Netherlands, and the US, it is striking that the Netherlands have a high proportion of part-time jobs while part-time jobs are less prevalent in France and in the US. Taking the model seriously, one expects employment and GDP per capita to be greater and GDP per hour to be lower in the former countries than in France, just as observed in the data. Without taxation, however, the model predicts that the most flexible country has the highest proportion of part-time jobs. Consequently, if one considers the US to be more flexible than France and the Netherlands, one should observe a greater proportion of part-time jobs in that country, which is clearly counterfactual. Adding taxes clears the picture. When taxation increases, the share of part-time work increases in the model in economies with high flexibility. The reverse is true in economies with low flexibility. The US has the lowest taxation rate. The Netherlands and France have high taxation rates. Hence, the model predicts that France has a lower fraction of part-time jobs, lower employment level and higher GDP per hour than the more flexible Netherlands. Finally, the model predicts that the Netherlands has a higher proportion of part-time jobs, similar employment levels and relatively high GDP per hour compared to flexible and low taxation countries like the US.

\subsubsection{Further Validation}

The model is not only consistent with static cross-country comparisons. The trend towards more employment and more production in the three countries under consideration can be explained by a change in the flexibility in contracting. For instance, the model can be used to understand the evolution of the measures of economic performance in the Netherlands in the last twenty years. In that country, high levels of cooperation between the government, the unions, and the employers have lead to repeated increases in labor market flexibility. Taxes, however, have remained high in that country. The model then predicts that both employment and the share of part-time jobs increase over the period. This implies that 
hours worked could either increase or decrease slightly, depending on whether the increase in employment dominates the increase in part-time or not. In terms of the measures of GDP, both GDP per capita and GDP per hour increase. GDP per hour should increase by a lot more, however. This is exactly what we observe in the Netherlands over the period.

Are both rigidities necessary for the results to arise in the model? To answer this question, the effects due to increased flexibility in wages from those due to increased flexibility in hours worked are separated in the next section.

\subsection{Partial Rigidity in Contracts}

In this section, situations in which the rigidity applies either only to wages or only to hours are discussed.

\subsubsection{Fixed Hours - Flexible Wages}

It is assumed first that there is a possibility of recontracting on the wage in every period, but that hours can be adjusted only with probability $\pi$. Once more, the effects of variations in the probability of recontracting and in the labor income tax are discussed. The results for $\pi=\{0.3,0.5,0.7\}$ can be seen in Table 8. In the economy with flexible wages but rigid hour choices, GDP per capita and per worker increase with the probability of recontracting. It is worth noting that GDP per hour also increases with $\pi$. These two features are explained by the behavior of employment and of the proportion of part-time jobs. Employment increases as the flexibility in adapting hours increases, but less and less. The proportion of part-time jobs increases when $\pi$ increases from 0.3 to 0.5 . It then decreases slightly. The result is that total hours worked is increasing in $\pi$, but by less than the increase in GDP per capita, which explains why GDP per hour is increasing in $\pi$.

Taxation has the same effect as in the economy of the previous section. GDP per capita is decreasing with $\tau$ while GDP per hour is increasing. Employment decreases when taxes are increased, and the proportion of part-time jobs increases. In terms of relative magnitude in the change in employment, taxes have the highest effect in the economy where $\pi=0.3$. Part-time jobs increase relatively more in the economy with $\pi=0.3$ than in the others when taxation moves from 0 to 0.5 , but it increases more in the economy with $\pi=0.7$ when $\tau$ increases from 0 to 0.3 . 
Table 8: Effects of variations in labor income tax - flexible wage

\begin{tabular}{lccc|ccc|ccc}
\hline \hline & \multicolumn{3}{c}{$\pi=0.3$} & \multicolumn{3}{c}{$\pi=0.5$} & \multicolumn{3}{c}{$\pi=0.7$} \\
$\tau$ & 0.0 & 0.3 & 0.5 & 0.0 & 0.3 & 0.5 & 0.0 & 0.3 & 0.5 \\
\hline GDP pc & 0.48 & 0.30 & 0.17 & 0.79 & 0.56 & 0.36 & 1.00 & 0.76 & 0.52 \\
GDP pwk & 0.37 & 0.09 & 0.03 & 0.93 & 0.32 & 0.14 & 1.00 & 0.52 & 0.25 \\
GDP ph & 0.61 & 0.98 & 1.27 & 0.71 & 1.03 & 1.23 & 1.00 & 1.25 & 1.45 \\
E & 0.76 & 0.29 & 0.16 & 0.99 & 0.57 & 0.39 & 1.00 & 0.68 & 0.49 \\
Part/Tot & 0.83 & 0.90 & 1.48 & 1.04 & 1.13 & 1.37 & 1.00 & 1.12 & 1.33 \\
\hline \hline
\end{tabular}

Notes: All variables are normalized by the values for parameters $\pi=0.7$ and $\tau=0.0$. $\mathrm{E}$ is employment, Part/Tot is part-time jobs divided by all jobs.

Notice that, as in the previous section, the model can account for differences across countries in terms of GDP per capita, employment, GDP per hour but the proportion of part-time jobs increases too much with a big increase in taxation in the most rigid economy.

\subsubsection{Fixed Wages - Flexible Hours}

When it is assumed that hours can be rebargained in every period, but that wage cannot necessarily be adjusted, the results are qualitatively similar to the situation in which both hours and wages are set in staggered fashion. Results pertaining to cases with $\pi=\{0.3,0.5,0.7\}$ can be found in Table 9 .

Table 9: Effects of variations in labor income tax - flexible hours

\begin{tabular}{lccc|ccc|ccc}
\hline \hline & \multicolumn{3}{c}{$\pi=0.3$} & \multicolumn{3}{c}{$\pi=0.5$} & \multicolumn{3}{c}{$\pi=0.7$} \\
$\tau$ & 0.0 & 0.3 & 0.5 & 0.0 & 0.3 & 0.5 & 0.0 & 0.3 & 0.5 \\
\hline GDP pc & 0.94 & 0.54 & 0.32 & 0.99 & 0.71 & 0.54 & 1.00 & 0.83 & 0.65 \\
GDP pwk & 0.79 & 0.24 & 0.08 & 0.96 & 0.49 & 0.30 & 1.00 & 0.72 & 0.46 \\
GDP ph & 1.01 & 1.27 & 1.48 & 0.99 & 1.16 & 1.29 & 1.00 & 1.10 & 1.22 \\
E & 0.84 & 0.44 & 0.26 & 0.97 & 0.70 & 0.54 & 1.00 & 0.87 & 0.71 \\
Part/Tot & 0.80 & 1.08 & 1.26 & 0.96 & 1.26 & 1.36 & 1.00 & 1.17 & 1.32 \\
\hline \hline
\end{tabular}

Notes: All variables are normalized by the values for parameters $\pi=0.7$ and $\tau=0.0$. E is employment, Part/Tot is part-time jobs divided by all jobs.

As in the two previous cases discussed, GDP per capita and GDP per worker increase with flexibility, although the rate of increase is decreasing and almost nil when one moves from $\pi=0.5$ to $\pi=0.7$. GDP per hour is almost unchanged when $\pi$ varies. Employment and the share of part-time jobs are increasing in $\pi$, but only slightly when one moves from $\pi=0.5$ to $\pi=0.7$. The effect of taxation is similar here than it is in the benchmark case, except for the behavior of the share of part-time jobs. Part-time jobs increase in the most 
rigid economy even with a small increase in taxation in this economy, while it varies very little and even decreases when $\tau$ increases from 0 to 0.3 in the benchmark case.

A special case in which there is rigidity in wages but in which the rigidity in hours does not matter is a situation in which part-time work is not an option. The results in that case are all similar to those in the benchmark case, with the exception of the effects on the proportion of part-time jobs in the economy.

Contrasting the results of the case in which only wages are rigid to those of the case where only hours are rigid is instructive. Note first that the rigidity in wages has very small effects on the various measures of GDP. The rigidity in hours has larger effects on these measures. The effects are similar in both partial-rigidity cases in terms of employment. Looking at the effects of partial rigidities on the share of part-time jobs, note that, when hours are flexible, the share increases at a decreasing rate as rigidities decrease. When wages are flexible, it increases at first and then starts decreasing. Finally, the effects of an increase in taxation are qualitatively similar in both cases, but the magnitude is smaller in the case where wages are flexible.

The interaction between the two types of rigidities is therefore necessary for the benchmark model to deliver the results described in Section 4.2.1.

\section{Conclusion}

Institutions explain performance. This paper shows that differences in labor market institutions and labor income taxation explain a constellation of measures of economic performance across countries. Our model economy is a two-sided matching model with ex-ante agent heterogeneity and idiosyncratic shocks in which labor/leisure choices and bargaining frictions are introduced. In such a model, a country with greater rigidity in wage setting and hour choices is stuck at a lower level of GDP per capita, lower level of employment and higher level of GDP per hour than a country with more flexibility. This arises because worker-firm pairs who would work part-time, were they given the possibility of changing the contract in the near future, are deterred from doing so by the rigidity. Hence, the proportion of part-time jobs is smaller in the economy with greater rigidity. On the other hand, the introduction of labor income taxes results in a smaller level of GDP per capita, a higher level of GDP per hour, a lower level of employment and a higher proportion of part-time jobs. The model, 
therefore, explains differences between the US, France, and the Netherlands.

More precisely, given that France is a country with higher wage and hour rigidities and high taxation, that the Netherlands is a country with less rigidity and high taxation, and the US has the lowest level of rigidity and the lowest level of income taxation, the model predicts that France has a low employment level, a low fraction of part-time jobs, a low GDP per capita and a high GDP per hour. It predicts that the Netherlands has a high employment level, an important fraction of part-time jobs, a low GDP per capita and a high GDP per hour, and it predicts that the US has a high employment level, a lower share of part-time jobs, a high level of GDP per capita and a low level of GDP per hour. All these features are clearly in the data.

\section{References}

Cooley, T. F., and G. D. Hansen (1995): "Money and the business cycle," in Frontiers of business cycle research, ed. by T. F. Cooley, chap. 7. Princeton University Press.

Danthine, S. (2005): "Two-Sided Search, Heterogeneity and Labor Market Performance," Discussion Paper 1572, IZA.

DÉlégation du SÉnat pour L’Union Européenne (1998): “Quelles Politiques de l'Emploi pour la Zone Euro," Rapport d'Information 388.

HaLl, R. E. (2003): "Modern Theory of Unemployment Fluctuations: Empirics and Policy Applications," American Economic Review Papers and Proceedings, 93(2), 145-150.

(2005): "Wage Determination and Employment Fluctuations," American Economic Review, 95(1), 50-65.

Handel, M. (2000): "Trends in Direct Measures of Job Skill Requirements," Working Paper 301, Jerome Levy Economics Institute.

McCann, D. (2005): Working Time Laws: A global perspective. Findings from the ILO's Conditions of Work and Employment Database. International Labour Organization.

Mendoza, E. G., A. Razin, and L. L. Tesar (1994): "Effective Tax Rates in Macro- 
economics: Cross-Country Estimates on Factor Income and Consumption," Journal of Monetary Economics, 34(3), 297-323.

Nickell, S., And J. VAN OuRs (2000): "The Netherlands and the United Kingdom: a European Unemployment Miracle?," Economic Policy, 30, 137-180.

OECD (2004): OECD Employment Outlook 2004. OECD.

Pissarides, C., P. Garibaldi, C. Olivetti, B. Petrongolo, and E. Wasmer (2005): "Women in the labor force: How well is Europe doing?," in European Women at Work, ed. by T. Boeri, D. del Boca, and C. Pissarides, pp. 1-56. Oxford University Press.

Prescott, E. C. (2003): "Why Do Americans Work So Much More Than Europeans?," Staff Report 321, Federal Reserve Bank of Minneapolis.

Shimer, R. (2004): "The Consequences of Rigid Wages in Search Models," Journal of the European Economic Association Papers and Proceedings, 2, 469-479.

- (2005): "The Cyclical Behavior of Equilibrium Unemployment and Vacancies: Evidence and Theory," American Economic Review, 95(1), 25-49. 


\section{Appendix}

Figure 7: Part-time jobs - whole population
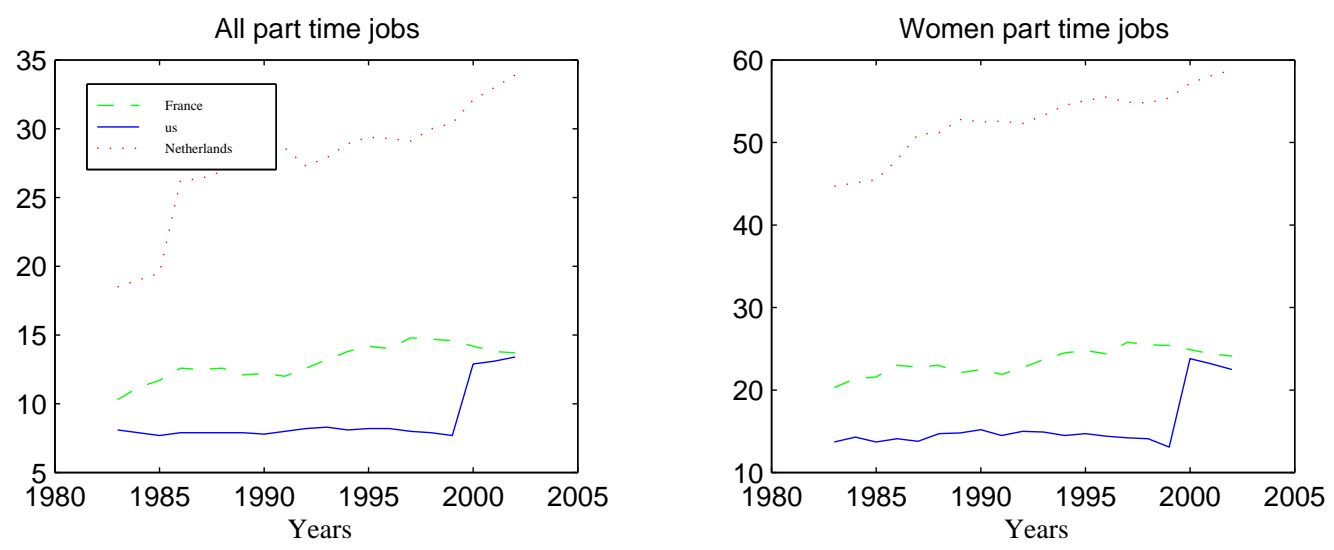
Figure 8: Part-time jobs - women
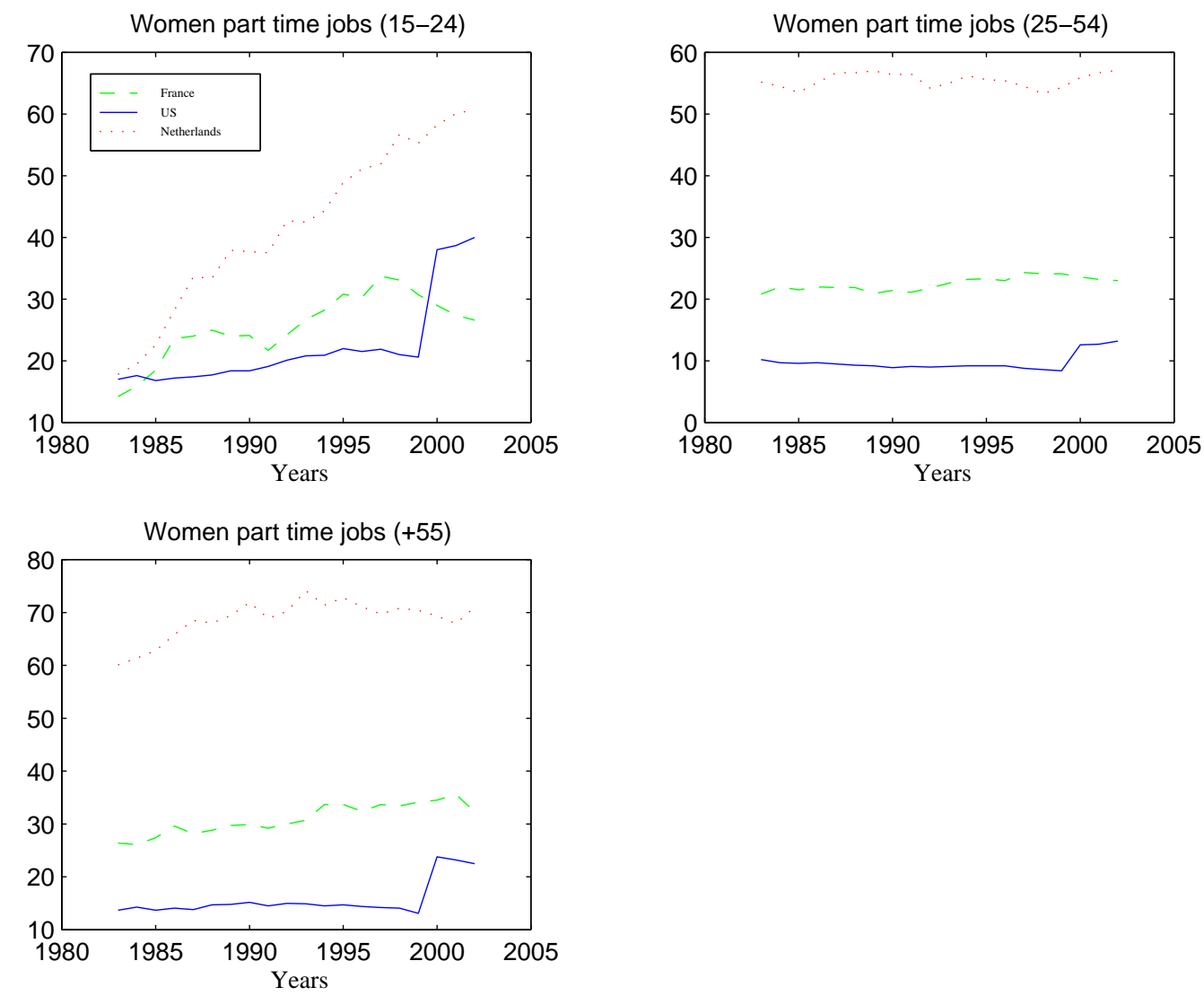

Source: OECD Statistical database. 
Figure 9: Part-time jobs - differences across age groups
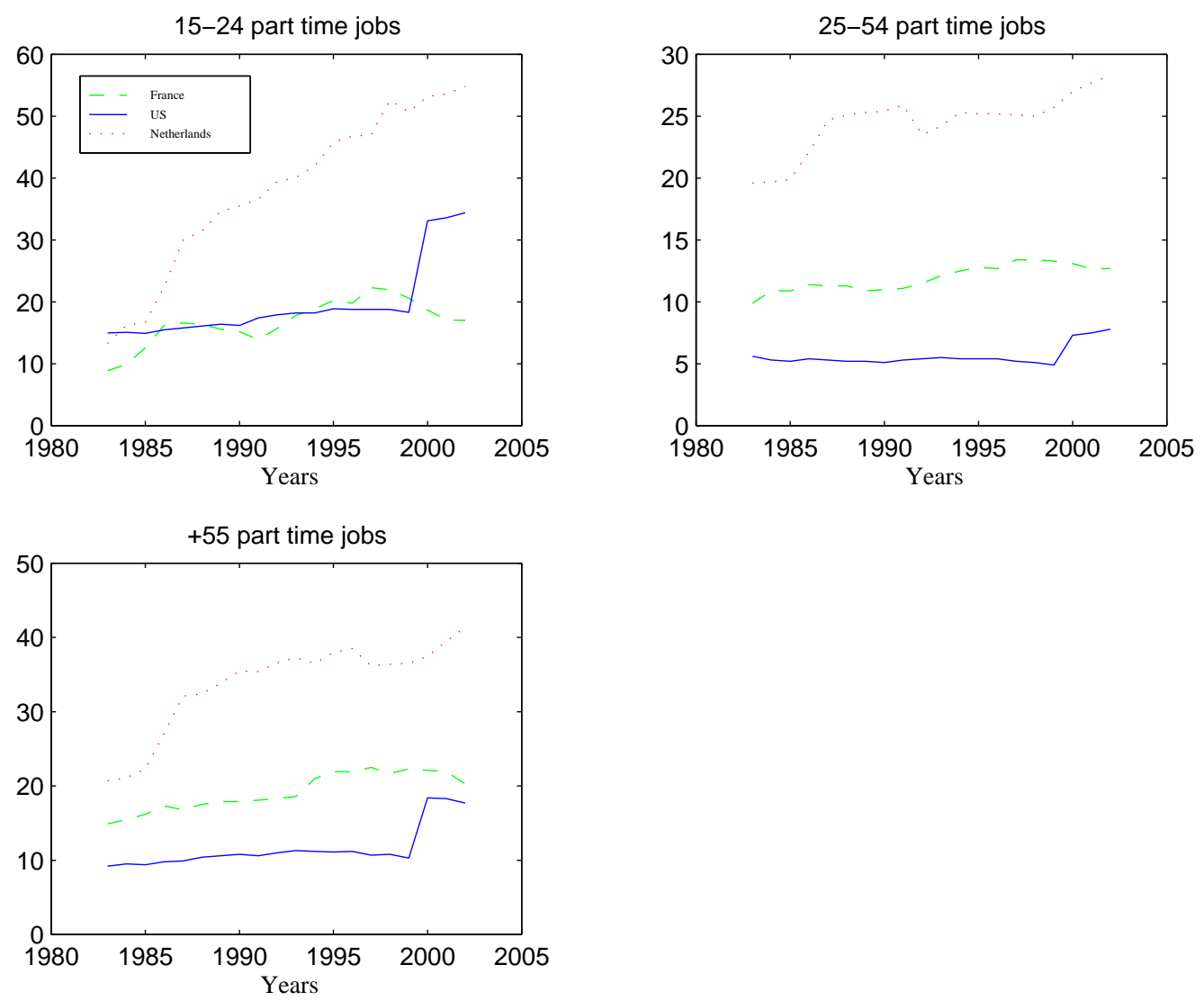

Source: OECD Statistical database. 
Figure 10: Weekly hours band 1985-2004 (\%)
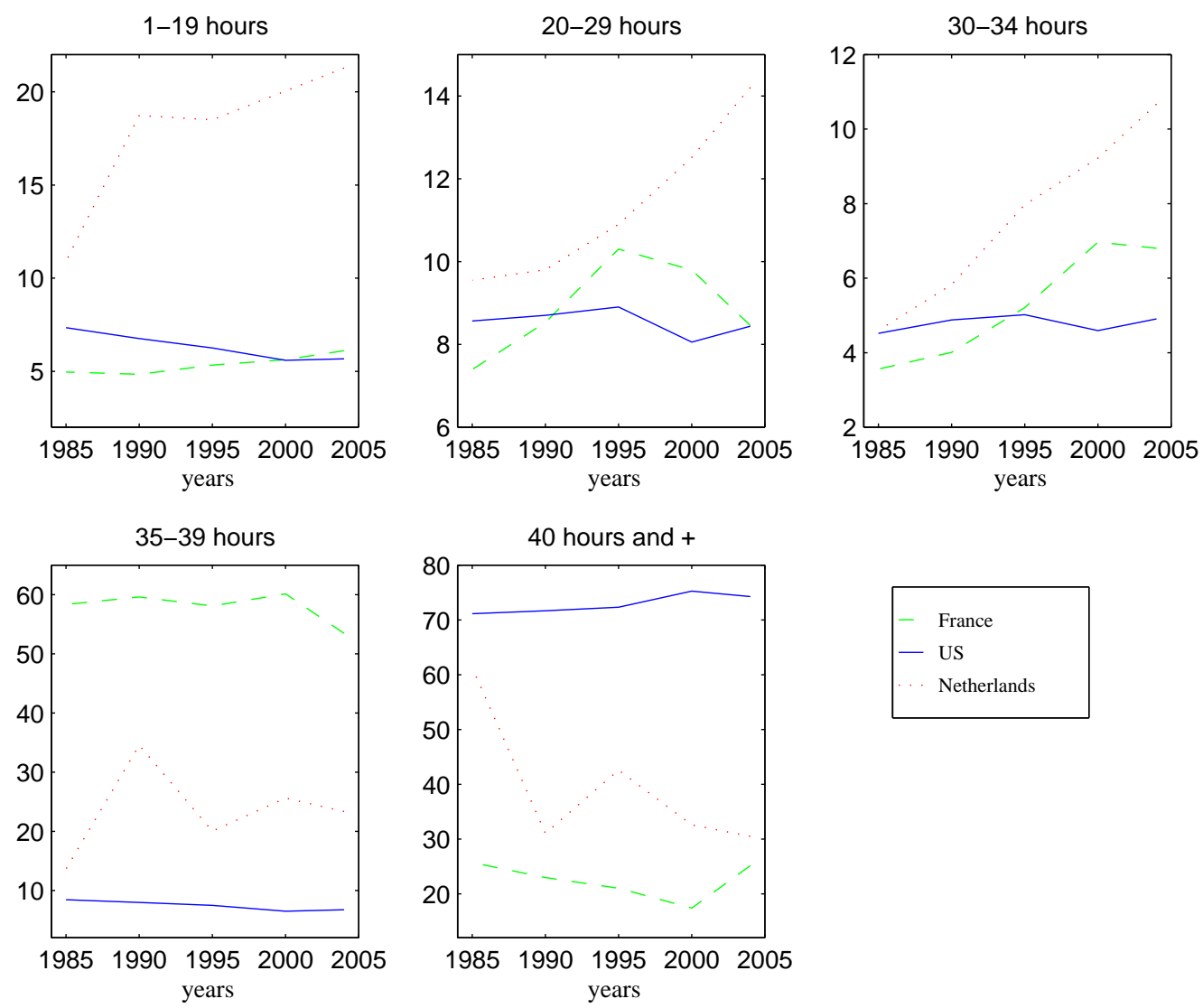

Source: OECD Statistical database. 